\title{
Analysis on the Application of Human Resources Accounting in Enterprise Human Resources Management
}

\author{
Lihua Dong \\ Ningxia Institute of Business and Technology, Yinchuan, 750021, China
}

Keywords: Human resource, Human resource accounting, Human resource management

\begin{abstract}
Human resources accounting could provide a more objective and clearer human resource costs and composition for the enterprise leaders. But the current related research on the application of human resource accounting in human resources management the enterprise in our country is insufficient. Most of the researches are expressing the objective necessity of human resource accounting in human resource management. Thus, this paper analyzes and discusses the application of human resource accounting in human resources management in the enterprise, and combines with advanced foreign human resource accounting experience to perfect the existing human resource accounting research in our country, and further puts forward the feasibility of management and human resource management level.
\end{abstract}

\section{Introduction}

Under the environment of knowledge economy, human resource has become the precious resources for the health sustained development of enterprise. The accounting and control for human resources and strengthening the internal level of enterprise human resources management are the inevitable choices of modern enterprise to adapt to the development of knowledge economy. Human resources accounting rises in the $60 \mathrm{~s}$ of last century. It mainly bases on human capital theories. In terms of the current status of China's economic construction, construction funds are still insufficient with relative less material resources. Only the amount of human resources is the most outstanding advantage in our country, and it needs further development and training.

\section{The overview of human resources accounting}

\section{The overview of human resources accounting}

Human resources accounting rises in the 60 s of last century and was introduced into China in 80 s. After thirty years of continuous evolution and perfection, a certain degree of theoretical system has formed. According to the classification of concept, it can be divided into human resources financial accounting and human resources management accounting, in which human resources accounting is a major research direction of the scholars in related fields at home and abroad ${ }^{[1]}$. Chinese scholars believe that human resources accounting refers to treat human resources as a kind of intangible assets, through the related theoretical basis of accounting disciplines to calculate the value and cost of human resources, through the calculation of the data to estimate the demand of the market, finally to seek a reasonable decision of human resources investment. It is a kind of accounting management methods ${ }^{[2]}$. It is easy to find that the main duty of human resources accounting is the collection and analysis of human resources information, and present the final result to enterprise managers to provide decision basis for the management. At the same time provide the general public as well as the relevant government departments with related information of enterprises to actively fulfill the social responsibility. 


\section{The current status of human resources accounting}

\section{Insufficient internal decision-making requirements}

In terms of the current status of enterprise management in our country, the information demand on human resources management is less and its importance is generally low. The required information can be acquired from the enterprise internal financial accounting, which leads that the business leaders don't think the enterprise development requires amount of human resources information or using the human resources accounting. In addition, there are still some enterprises understand the current situation of enterprise development in our country, and actively adapt to the social development needs, attaches great importance to the human resources accounting. But because the related research theory is insufficient in our country, and the theoretical foundation is too weak, it has not been able to compare with the human resources accounting standard in Europe and America. And there are great difficulties in practical application, thus we walked a lot of detours, and even the final cost is out of step with the benefits, wasted a lot of manpower and material resources and financial resources, virtually increased the difficulties for Chinese enterprise to apply human resources accounting in human resources management and seriously restricts the sustainable development of enterprise.

\section{Difficulty in benefit valuation}

Because the human resources accounting theory system is relatively mature, Europe, America and other western countries in the process of human resources management can apply it flexibly. Through human resources accounting, they can objectively reflect the values of the human resources and costs, and market demand can be fully investigated to provide decision-making basis for the human resources investment. Compared with western countries, China's human resources accounting application level is relatively backward. The human resources accounting could only provide enterprise managers with the information in human resources investment spending. Though for a nation, the human resources accounting can assess the contribution of education investment for the growth of national economy, compared with companies, this budget is still difficult to adapt to the modern enterprise development, also is not economic enough ${ }^{[3]}$. The reason is mainly because that the revenue and profit of enterprise are mostly got through the sales management, rarely by human resources. In the process of product sales, the benefits are hard to indentify from the revenue of the human resources investment, or the income acquired from human resources investment. It causes the importance of human resources investment is getting smaller and formed the situation now.

Insufficient information disclosure regulation

The current situation of enterprise information disclosure in China is poor. There are a lot of distortions in information disclosure, which seriously restricts the sustainable development of enterprise. In addition, because the external mandatory information disclosure regulation is relatively limited, enterprises are difficult to get more valuable information in the investment decision-making, which is the main cause of the insufficient power for enterprise to use human resources accounting ${ }^{[4]}$. Thus it can be seen that human resource is the indispensable asset in enterprise development, at the same time it also is the strong impetus to guarantee the sustainable development of the enterprise. The lack of information disclosure directly leads to the lack of information openness, transparency and objectivity, which is not conducive for the healthy sustained development of enterprise.

\section{The importance of applying human resources accounting in enterprise human resources management}

\section{Provide a new measurement method for the human resources management work}

The human resources management work mainly includes staff recruitment, selection, employment relationship establishment and a series of activities. It is mainly in order to meet the human resources demand of enterprise development and market demand. First, you need to forecast the demand of human resources. After the human resources management activity, budget for human resources acquirement needs to be clarified, and the human resources accounting is to ensure that this kind of 
work can be carried out, and provides scientific and reasonable calculation method to put forward predictive suggestions with practical value which combines the needs of enterprise human resources development.

In terms of the value of human resources itself, it is the starting point of human resources management work. Furthermore, it is through a series of human resources management work to refine the human resources value, and comprehensively optimize the overall value. It is not hard to see that analysis, design, selection, human resource development, configuration, and salary payment to the enterprise internal work are no longer limited to work link, and become the strategy to optimize enterprise human resources value. Thus, human resources accounting will be valued and applied by more enterprises.

\section{Contribute to the balance of enterprise human resources}

Human resources maintenance mainly refers to the general effect of the population system established by individual values. In the process of human resources management, enterprise should always pay attention to the rational allocation of human resources in order to mobilize employees' personal ability and motivation. It helps to improve the overall efficiency and create a good working atmosphere. On the contrary, if the enterprise values less on the ability and the effect of personnel, it will bear the cost of human resources training, resulting in the loss of a large amount of money. Human resources accounting reveals the impact of the loss of human resources for enterprise development and economic losses through calculation of the personnel retrain cost and combine with the operation and development situation of the enterprise ${ }^{[5]}$. In addition, because the human resources accounting can reveal signs of relevant human resource group through data measurement, it can provide early warning for enterprise management. Then by the related human resources management personnel clarify the development trend before the actual problem and then through a series of scientific and reasonable means to keep the balance of the enterprise human resources.

As for the configuration of human resources, first we need to consider the staff's own value and the skills they mastered, reasonably arrange job and task combining with the enterprise internal human resource requirements. It requires the enterprise make reasonable configuration of human resource, and arranges the most suitable person to the right post, and gives employees opportunities to study in work so that employees' potential could get maximum excitation and create greater value. In general, human resources allocation needs to follow the rationality to guarantee the human resources allocation can improve work efficiency, employee satisfaction and human resources development optimization.

\section{The application of human resources accounting in human resources management}

\section{Human resource flow}

Human resources accounting plays an indispensable role in the enterprise human resources management. It is mainly used in the treatment of employee turnover, employee compensation and HR project evaluation. Among which the human resource flow mainly refers to the appropriate personnel flow in the process of development which has the effect of catalyst, and stimulates the benign competition between employees, creates a good working atmosphere and vitality. But human resource flow needs to be moderate. If the turnover is too frequent, it will have negative impact to the enterprise, such as wasting a lot of training costs, and makes employees lose the sense of belonging and responsibility and affects the work efficiency. In terms of the present situation in our country's human resources market, it is in the situation of oversupply, so that many enterprises don't pay too much attention on the loss of human resources, and it inadvertently caused the loss of enterprise cost.

Human resources accounting can reveal the internal loss caused by the personnel loss through a series of scientific and reasonable measures to enable enterprises fully improve the cognitive attitude and reduce the loss caused by human resource flow. For example, the initial cost of a senior supervisor in a company is 200 thousand Yuan, and the training fee is 50 thousand Yuan, while the 
supervisor's personal value is 1 million Yuan, and the expected term is five-year with the annual salary of 100 thousand Yuan. And the base year value of this supervisor is 1.25 million Yuan, 1.3 million Yuan in the first year, and 1.5 million Yuan in the second year. From which it is not hard to see that if the supervisor leaves one year later, he will bring 1.3 million Yuan of economic losses for enterprises, and also need to pay the training costs 200 thousand Yuan for compensation. It brings immeasurable loss for enterprise.

\section{Reasonable arrangement on employee salary}

For employees, the enterprise benefits are the most interesting prerequisites, and what kind of benefits can attract more excellent talents, and the talent training cost can not be too high, it is the problem every enterprise will consider when recruiting talent. The salary for human resources, although paid by enterprises, is mostly determined by the demand of market. In modern society, the value of human resources is mainly measured through monetary. Related scholars put forward a series of views, including the future salary discount model as the most representative model. It thinks that salary discount is the embodiment of the value of the staff. This view has obvious drawbacks. This model reverses the primary and secondary. Employee' s salary discount value is affected by many factors, including the cause of the market, and non-market factors will also affect the employee's salary discount with huge fluctuation. In such cases, the function of human resources accounting should be fully exerted, improve and perfect the corresponding salary mechanism. Through the staff training costs, health care investment and the corresponding data conversion to comprehensively considerate human resource value.

\section{Help to solve the human resources development budget}

The human resources management personnel first needs to consider the value of human resources development and investment of human resource configuration problems in combination with internal demand and the needs of society at the same time; the second is the cost budget of the investment in human resources. Ensure that the value created by human resource is higher than the cost value. So, the human resources management personnel will make comprehensive analysis based on human resources investment yield return rate, in combination with the practical operating conditions of the enterprise, provide scientific and rational investment decisions for enterprise decision makers. In addition, the evaluation on human resource value is the guarantee to the premise of accurate making for the human resources development budgets. It needs to carry out a series of activities by organizing workers to further reveal the employees' work performance and future development potential and create value in the process of enterprise development. Through a series of means and reasonable compensation, human resources accounting fully arouses the enthusiasm of staff, and creates a good working environment, improves the work efficiency.

\section{Accurate evaluation on the project value of human resource}

The human resources department has an indispensable role in the enterprise internal composition. The quality of human resource configuration will directly affect the overall working efficiency and economic benefits of the enterprise. It connects with other departments directly in the process of working, and provides creative and cost services in the corresponding period of time for other departments and gives full play to the human resource value. For example, the human resources management department may set up a set of performance incentive mechanism to fully arouse the enthusiasm of the employees and in turn improve customer service levels and the quality of products and reduce cost. Secondly, in order to take more comprehensive considerations of contribution made by human resources for enterprise, it needs to combine with the corresponding functional activities to evaluate human resource's contribution rate of return to the enterprise to guarantee the accuracy and integrity of the evaluation, and provide effective decision-making information for managers, which takes up positive advantage in the fierce market competition. 


\section{Conclusion}

Above all, the application of the human resources accounting in the human resources management is very essential, especially for some enterprise with higher technical requirements, human resources activities are relatively dense, and the application effect is evident. Thus, formulate scientific and rational human resources accounting system can ensure that enterprises could carry out practical work with plan and focus. It is the current primary research in the field of management direction and accounting, and it also can deepen the cognition of the enterprise for human resources accounting.

\section{References}

[1] Chen Zinan, Lian Shenhua. A preliminary study on the application of human resources accounting in the enterprise human resources management. Journal of Economist, 2012 (9) : 207.

[2] Zhang Di, Li Weihua, The application of human resources accounting in the enterprise human resources management. Journal of Decision Research, 2011 (18) : 53-53.

[3] Wang Hui. The research on the application of human resources accounting in the enterprise human resources managemen. China Ocean University, 2012 (26) : 26-27.

[4] Luo Zhengqing, Jiang Tianyuan. The application of human resources accounting in the enterprise human resources management. Journal of Human Resources Management (Academic), 2014 (2) : 156-158.

[5] Chen Zinan, Wu Hongfei. A preliminary study on the application of human resources accounting in the enterprise human resources management. Journal of Zhejiang Statistics, 2011 (8): 48-3. 